\title{
PERMIAN PHYTOGEOGRAPHY AND CLIMATE
}

ZIEGLER*, Alfred M., Dept. of the Geophysical Sciences, University of Chicago, Chicago, IL 60637, U.S.A.; GYLLENHAAL, Eric D., Dept. of the Geophysical Sciences, University of Chicago, Chicago, IL 60637, U.S.A.

A greater number of floral provinces have been defined for the Permian than for any other Phanerozoic period, and this is presumably the reflection of a well differentiated set of climate zones. These floras have been assigned to an idealized set of ten "biomes" as defined on the basis of the equator-to-pole spectrum of present day climates (Ziegler, 1990). The biomes reflect temperature and precipitation, and in particular the way in which these parameters change through the annual cycle. The purpose of the present paper is (1) to expand the taxonomic database of Permian floras and climatically sensitive sediments, (2) to use ordination analyses and other multivariate techniques to relate taxonomic data to climate, geographic distance and other factors that controlled the global distribution of plants, and (3) to relate these results to the recognition of biomes during the Permian.

This approach reveals that the phytogeographic provinces, as recognized by paleobotanists, are objectively valid entities, but significant gradations can be detected, supporting the idea that the floras were controlled by climate rather than by geographic separation. In fact, there are no examples in the Permian world of strictly geographic barriers, which is not surprising in view of the fact that the continents were basically together through this time.

Biomes are defined by climatic parameters, but the taxonomic characteristics of biomes have evolved with time. The Permian floral provinces can be related to precipitation balance by their associations with such climatically sensitive sediments as coals, paleosols and evaporites, and this is critical for assigning each to an appropriate biome. At least at the generic level, taxonomic lists have significant limitations for identification of biomes in the geologic past. In particular, northern and southern hemisphere temperate biomes evolved radically different floras by the Permian. Ecomorphic characters and taxonomic diversity within critical groups may provide a more general scheme for phytologic recognition of biomes through geologic time.

Finally, detailed comparisons will be made to General Circulation Model and Energy Balance studies on the Permian. The numerical studies seem to overemphasize the seasonal extremes of temperature in the middle to high latitudes. 